\title{
Detection and Analytical Capabilities for Trace Level of Carbon in High-Purity Metals by Laser-Induced Breakdown Spectroscopy with a Frequency Quintupled 213 nm Nd:YAG Laser
}

\author{
Masaki Ohata ${ }^{1}$ and Toshiki Nakae ${ }^{2}$ \\ ${ }^{1}$ Inorganic Standards Group, Research Institute for Material and Chemical Measurement (MCM), \\ National Metrology Institute of Japan (NMIJ), National Institute of Advanced Industrial Science and Technology (AIST), \\ No. 1-1-1, Umezono, Tsukuba, Ibaraki 305-8563, Japan \\ ${ }^{2}$ Electronics Equipment Division, Hakuto Co., Ltd., No. 1-13, Shinjuku 1-Chome, Shinjuku-Ku, Tokyo 160-8910, Japan
}

Correspondence should be addressed to Masaki Ohata; m-oohata@aist.go.jp

Received 17 November 2016; Accepted 24 January 2017; Published 20 February 2017

Academic Editor: Alexandre Giuliani

Copyright (c) 2017 Masaki Ohata and Toshiki Nakae. This is an open access article distributed under the Creative Commons Attribution License, which permits unrestricted use, distribution, and reproduction in any medium, provided the original work is properly cited.

\begin{abstract}
The laser-induced breakdown spectroscopy (LIBS) with a frequency quintupled $213 \mathrm{~nm}$ Nd:YAG laser was examined to the analysis of trace level of carbon (C) in high-purity metals and its detection and analytical capabilities were evaluated. Though $\mathrm{C}$ signal in a wavelength of $247.9 \mathrm{~nm}$, which showed the highest sensitivity of C, could be obtained from Cd, Ti, and $\mathrm{Zn} \mathrm{ca.} 7000 \mathrm{mg} \mathrm{kg}{ }^{-1} \mathrm{C}$ in Fe could not be detected due to the interferences from a lot of Fe spectra. Alternative C signal in a wavelength of $193.1 \mathrm{~nm}$ could not be also detected from $\mathrm{Fe}$ due to the insufficient laser output energy of the frequency quintupled $213 \mathrm{~nm} \mathrm{Nd}$ :YAG laser. The depth analysis of $\mathrm{C}$ by LIBS was also demonstrated and the $\mathrm{C}$ in $\mathrm{Cd}$ and $\mathrm{Zn}$ was found to be contaminated in only surface area whereas the $\mathrm{C}$ in Ti was distributed in bulk. From these results, the frequency quintupled $213 \mathrm{~nm}$ Nd:YAG laser, which was adopted widely as a commercial laser ablation (LA) system coupled with inductively coupled plasma mass spectrometry (ICPMS) for trace element analysis in solid materials, could be used for $\mathrm{C}$ analysis to achieve simultaneous measurements for both $\mathrm{C}$ and trace elements in metals by LIBS and LA-ICPMS, respectively.
\end{abstract}

\section{Introduction}

The light elements such as carbon $(\mathrm{C})$, hydrogen $(\mathrm{H})$, nitrogen $(\mathrm{N})$, and oxygen $(\mathrm{O})$ play a significant role in determining important mechanical and physical properties for almost all solid materials. For example, the existence of trace level of light elements is very desirable in steel, and it was well known that $\mathrm{C}$ is the most important element in steel production $[1,2]$. It is well known that spark discharge optical emission spectrometry and classical combustion C analyser are common analytical techniques for $\mathrm{C}$ in solid materials such as steel and metals [3, 4]. Laser ablation inductively coupled plasma mass spectrometry (LA-ICPMS) has increasingly been used for the determination of trace elements with high spatial lateral and depth resolutions and low limits of detection below $1 \mathrm{mg} \mathrm{kg}^{-1}$ in many different solid materials such as industrial materials, geological samples, and human remains [5-13]. However, the analytical technique was not suited for the trace light element analysis due to its harsh spectroscopic interferences from air $\left(\mathrm{N}_{2}, \mathrm{O}_{2}\right.$, and $\left.\mathrm{CO}_{2}\right)$ and humidity $\left(\mathrm{H}_{2} \mathrm{O}\right)$ that might be introduced into the ICP. Alternative analytical technique that uses the LA is laser-induced breakdown spectroscopy (LIBS) [1424]. The LIBS shows several technical benefits that include little or no sample preparation, no contamination from the excitation source, and direct characterization of molten and solid materials as an almost nondestructive technique. In this context, it is worth noting that X-ray fluorescence (XRF) spectrometry, the main competing technique to LIBS, has been virtually impossible for the detection of trace level 
of light elements. In recent years, the detection power of LIBS was improved due to the instrumental developments of sensitive optical detectors such as intensified charge coupled device (ICCD). In addition, both LIBS and LA have been incorporated into a single commercial instrument as tandem LA/LIBS and the determinations of light and heavy elements simultaneously by LIBS and LA-ICPMS, respectively, have been demonstrated [25-30]. From these points of view, the tandem LA/LIBS could be useful for the determination of trace level of light elements in solid materials such as metals; however, the analytical applications were limited compared to those demonstrated by conventional LIBS with either $1064 \mathrm{~nm}$ or $532 \mathrm{~nm}$ Nd:YAG lasers. Therefore, it is worthwhile to evaluate the detection and analytical capabilities of tandem LA/LIBS for the determination of trace level of light elements in solid materials.

The purpose of the present study was the evaluation of the detection and analytical capabilities of trace level of $\mathrm{C}$ in high-purity metals by LIBS with a frequency quintupled $213 \mathrm{~nm}$ Nd:YAG laser, which could be equipped as tandem LA/LIBS for both LIBS and LA-ICPMS analyses. The highpurity metals such as cadmium $(\mathrm{Cd})$, iron $(\mathrm{Fe})$, titanium $(\mathrm{Ti})$, and zinc $(\mathrm{Zn})$ were measured and the operating conditions of the tandem LA/LIBS such as laser irradiated diameter and chamber gases for both $\mathrm{Ar}$ and He were examined. The depth analysis of $\mathrm{C}$ was also demonstrated and the figures of merit of the LIBS with a frequency quintupled $213 \mathrm{~nm}$ Nd:YAG laser were determined in the present study.

\section{Experimental}

2.1. Instrument. Table 1 lists the experimental conditions of the LIBS instrument used in the present study. All experiments were performed using a J200 Tandem LA/LIBS Instrument with HP detector option (Applied Spectra Inc., Fremont, CA) equipped with a $213 \mathrm{~nm}$ frequency quintupled Nd:YAG nanosecond pulsed laser, which was designed for both LIBS and LA-ICPMS measurements. For collection and spectroscopic analysis of the radiation emitted by the laserinduced plasma (LIP), an optical fiber system connected to a Czerny-Turner spectrometer with ICCD detection was employed. For every laser shot, spectra over the wavelengths ranged from 220 to $280 \mathrm{~nm}$ or 160 to $220 \mathrm{~nm}$ for $247.9 \mathrm{~nm}$ or $193.1 \mathrm{~nm}$ C analyses, respectively, were recorded in Axiom data acquisition software provided by the manufacturer of the instrument. In order to avoid continuum emission and accumulate $\mathrm{C}$ emission signal from LIP, $0.1 \mu$ s and $5 \mu$ s of gate delay and width were set, respectively, as listed in Table 1. The ablation chamber could accommodate samples of up to $100 \mathrm{~mm}$ diameter with flexibility in volume and wash-out time. Either Ar or He was used for the chamber gas to remove carbon contamination from carbon dioxide $\left(\mathrm{CO}_{2}\right)$ in ambient air.

2.2. Samples. The metal samples of $\mathrm{Cd}, \mathrm{Fe}, \mathrm{Ti}$, and $\mathrm{Zn}$ were used in the present study. The metal Cd had granular shape and its nominal value of the purity was $99.999 \%$ (Wako Pure Chemicals, Japan). The Fe was carbon steel with rectangular parallelepiped block $(3 \mathrm{~mm} \times 10 \mathrm{~mm} \times 15 \mathrm{~mm})$
TABLE 1: Operating conditions of tandem LA/LIBS instrument (J200 HP).

\begin{tabular}{|c|c|}
\hline LIBS instrument & J200 HP (Applied Spectra) \\
\hline Laser wavelength, nm & 213 \\
\hline Laser output level & $\begin{array}{c}80 \text { (estimated at } 3.5 \mathrm{~mJ} \text { laser output } \\
\text { energy) }\end{array}$ \\
\hline Spot size, $\mu \mathrm{m}$ & $15,50,100$ \\
\hline Repetition rate, $\mathrm{Hz}$ & 10 \\
\hline $\begin{array}{l}\text { Carrier } \mathrm{He} \text { or Ar gas flow } \\
\text { rate, } \mathrm{L} \mathrm{min}^{-1}\end{array}$ & 0.50 \\
\hline Ablation pattern & Single spot \\
\hline Shot number & 300 \\
\hline Spectrometer & UV sensitive Czerny-Turner \\
\hline Detector & ICCD \\
\hline Gate delay, $\mu \mathrm{s}$ & 0.10 \\
\hline Gate width, $\mu$ s & 5 \\
\hline $\begin{array}{l}\text { Accumulation time for one } \\
\text { LIBS spectrum, s }\end{array}$ & 1.0 \\
\hline Detector gain & $\begin{array}{l}60 \text { for } 247.9 \mathrm{~nm} \mathrm{C} \text { measurements in } \\
\text { Zn, Ti, Cd, Fe } \\
80 \text { for } 193.1 \mathrm{~nm} \mathrm{C} \text { measurement in Fe }\end{array}$ \\
\hline Grating, grooves $\mathrm{mm}^{-1}$ & 2400 \\
\hline Acquisition mode & Multiple shots \\
\hline
\end{tabular}

which contained $0.673 \%$ in mass fraction of C (NMIJ CRM 1015-b) and the value was certified by National Metrology Institute of Japan (NMIJ, Tsukuba, Ibaraki, Japan). The Ti used had columnar form (ca. $0.12 \mathrm{~g}$ ) and the concentration of C was $0.009 \%$ in mass fraction (LECO RM 502-876, LECO Japan Corporation, Osaka, Japan), which was commercially available as calibration standard for oxygen combustioninfrared absorptiometry for $\mathrm{C}$ analysis. The metal $\mathrm{Zn}$ used in the present study was NMIJ CRM 3009-a, whose purity was certified as $99.995 \%$ in mass fraction by NMIJ. The form of the $\mathrm{Zn}$ was $2 \mathrm{~mm}$ cubic (ca. $0.14 \mathrm{~g}$ ) and the concentration of $\mathrm{C}$ was $2-6 \mathrm{mg} \mathrm{kg}^{-1}$ which was determined by oxygen combustion-infrared absorptiometry calibrated by the calibration standard of steel pin from LECO Corporation. The sample pretreatment such as surface cleaning using acids was not carried out for all metal samples used in the present study.

\section{Results and Discussion}

3.1. LIBS Spectra from Different Laser Irradiated Diameter. Figure 1 shows LIBS spectra obtained from the different laser irradiated diameters of 15,50 , and $100 \mu \mathrm{m}$ with respect to the surface of $\mathrm{Zn}$ metal. The chamber gas was Ar and the laser irradiated output energy to the surface of $\mathrm{Zn}$ was fixed at $3.5 \mathrm{~mJ}$. As can be seen from Figure 1, the huge spectrum from $\mathrm{Zn}$ was observed at closer wavelength with respect to $247.9 \mathrm{~nm}$ of $\mathrm{C}$ spectrum, which could influence the C analysis. The $\mathrm{C}$ signal observed for $50 \mu \mathrm{m}$ laser irradiated diameter showed higher intensity than that observed for $15 \mu \mathrm{m}$, which resulted in better net signal intensity and signalto-background $(\mathrm{S} / \mathrm{B})$ ratio since the background spectra were 


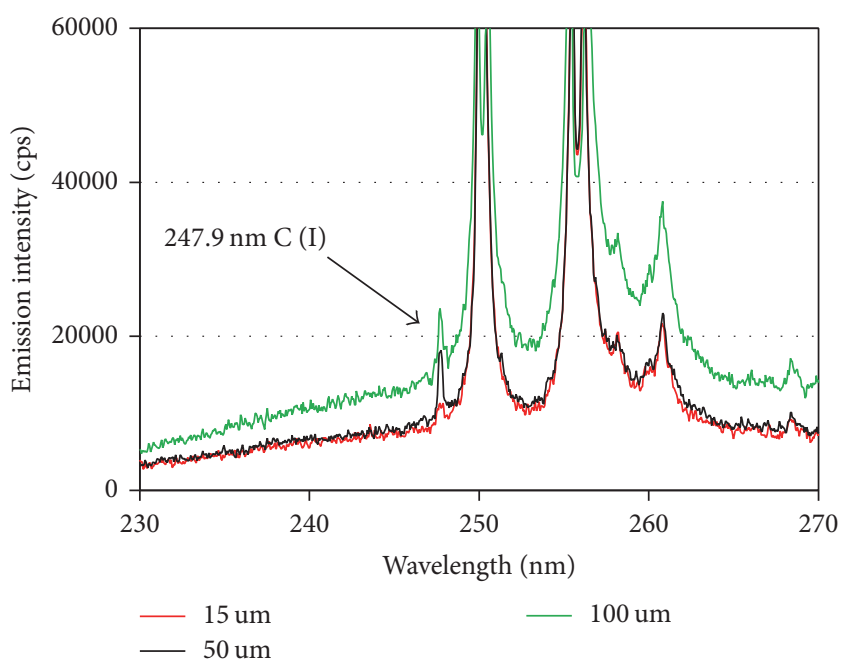

FIGURE 1: LIBS spectra obtained from the different laser irradiated diameters of 15,50 , and $100 \mu \mathrm{m}$ with respect to the surface of $\mathrm{Zn}$ metal. The chamber gas was Ar and the laser output energy to the surface of $\mathrm{Zn}$ was fixed at $3.5 \mathrm{~mJ}$.

similar to each other. On the other hand, similar net signal intensity but poor S/B ratio of C was observed for $100 \mu \mathrm{m}$ laser irradiated diameter, since the background spectrum observed, which was attributed to both the matrix element of $\mathrm{Zn}$ and the continuous emission from Ar-LIP, was higher than those for both 15 and $50 \mu \mathrm{m}$ even though the highest $\mathrm{C}$ signal intensity was observed. From these results, the laser irradiated diameter of $50 \mu \mathrm{m}$ was selected for $\mathrm{C}$ analysis in metal samples by LIBS with $3.5 \mathrm{~mJ}$ laser output energy in the present study.

3.2. LIBS Spectra from Different Chamber Gases of Ar and $H e$. The different chamber gases between Ar and He were examined in the present study. Figure 2 shows the LIBS spectra from Zn metal obtained under either Ar or He gas condition. In case of Ar, both lager net signal intensity of $\mathrm{C}$ and higher background spectrum were observed compared to those of He. The higher S/B ratio of $\mathrm{C}$ could be obtained under He gas condition even though the net signal intensity was smaller since background spectrum was lower, as shown in Figure 2. The lower background emission spectrum could be due to the lower thermal conductivity of $\mathrm{He}$, which made thermal expansion faster and reduced electron number density of the LIP, compared to that of Ar. Also He has higher ionization potential than that of Ar and leads to less dense electron number density to produce lower background of $\mathrm{He}-$ LIP [31]. Figures 3 and 4 show the LIBS spectra observed for metal samples of $\mathrm{Cd}$ and $\mathrm{Ti}$, respectively. In case of $\mathrm{Cd}$, similar background spectra were observed for both gases; however, higher $\mathrm{C}$ signal intensity could be obtained under Ar chamber gas condition. The higher $\mathrm{C}$ signal intensity could be attributed to the Ar-LIP which revealed greater electron concentration leading to enhancing the emission signal compared to that of He-LIP. On the other hand, the background emission spectrum was attributed to not only continuous emission from Ar-LIP but also spectra from matrix element of Cd. As can be seen in Figure 3, Cd spectra were not close to $247.9 \mathrm{~nm} \mathrm{C}$, which resulted in the lower background emission intensity with respect to the $\mathrm{C}$ spectrum; therefore, better net signal intensity and $\mathrm{S} / \mathrm{B}$ ratio of $\mathrm{C}$ could be observed from $\mathrm{Cd}$ metal. In case of Ti, higher background spectrum and higher Ti spectra were observed under Ar gas condition; however, similar net C signals could be obtained for both chamber gas conditions as shown in Figure 4 . Consequently, better S/B ratio of $\mathrm{C}$ could be observed under $\mathrm{He}$ gas condition for Ti metal. In case of Fe, though the concentration of $\mathrm{C}$ was $0.673 \%$ in $\mathrm{Fe}$, it could not be detected since many Fe spectra interfered withj the $\mathrm{C}$ spectrum for both gas conditions (data is not shown). The $\mathrm{C}$ in Fe could not be also detected by alternative wavelength of $193.1 \mathrm{~nm}$ of $\mathrm{C}$, which could be expected to get rid of the Fe spectral interferences. In previous studies [14$18,20,22], \mathrm{C}$ in Fe could be detected by LIBS, but the laser output energy applied was higher $(100 \mathrm{~mJ})$ than that of the tandem LA/LIBS used in the present study $(3.5 \mathrm{~mJ})$ since the laser wavelength used was $1064 \mathrm{~nm}$. From these results, the insufficient sensitivity of $\mathrm{C}$ was considered to be due to the insufficient laser output energy of the frequency quintupled $213 \mathrm{~nm}$ Nd:YAG laser. It could be considered that $266 \mathrm{~nm}$ $\mathrm{Nd}$ :YAG laser might be useful for the measurement of $\mathrm{C}$ in $\mathrm{Fe}$ in a wavelength of $193.1 \mathrm{~nm}$ since the laser could give higher output energy of $c a .25 \mathrm{~mJ}$ laser. Unfortunately, though the simultaneous measurements for both $\mathrm{C}$ in the concentration of sub \% and trace elements in Fe using the tandem LA/LIBS with $213 \mathrm{~nm}$ Nd:YAG laser coupled with ICPMS was difficult, it could be evaluated that the simultaneous measurement was possible for other metals such as $\mathrm{Cd}$, Ti, and $\mathrm{Zn}$. Though Ar chamber gas showed better sensitivity of $\mathrm{C}$ on $\mathrm{Cd}$ metal, it could be considered that He gas was suitable when the LIBS was carried out as tandem LA/LIBS with ICPMS, since the gas was known to be suitable for LA-ICPMS.

3.3. Depth Analysis of C by LIBS. It is well known that the LIBS can be applied to the depth analysis of elements in solid materials [32-35]. The examination on the distribution of elements including light elements is also important to characterize the solid materials. Therefore, depth analysis of $\mathrm{C}$ was examined in the present study. The analytical results obtained under both $\mathrm{Ar}$ and $\mathrm{He}$ gas conditions were shown in Figures 5-7 for $\mathrm{Zn}, \mathrm{Cd}$, and Ti metals, respectively. The 300 laser shots resulted in $c a .90 \mu \mathrm{m}$ depth analysis of $\mathrm{C}$ in these metals. As could be seen from Figures 5-7, both $\mathrm{C}$ and background emission signals decreased with increasing depth which could be due to the laser beam defocusing during laser shots with respect to sample surface. The trends of signals might be also dependent on the sample form (cubic, granular, and columnar forms for $\mathrm{Zn}, \mathrm{Cd}$, and $\mathrm{Ti}$, resp.). As can be seen in Figures 5 and 6, C signals could be obtained from only the surface area of both $\mathrm{Zn}$ and $\mathrm{Cd}$ metals. That is, the $\mathrm{C}$ in both metals was not distributed in bulk. It was considered that $\mathrm{C}$ on the surface of these metals might be the contamination which could be due to the surface oxidation from ambient air during their storage period. Though the concentration of $\mathrm{C}$ in $\mathrm{Zn}$ was from 2 to $6 \mathrm{mg} \mathrm{kg}^{-1}$ which was 


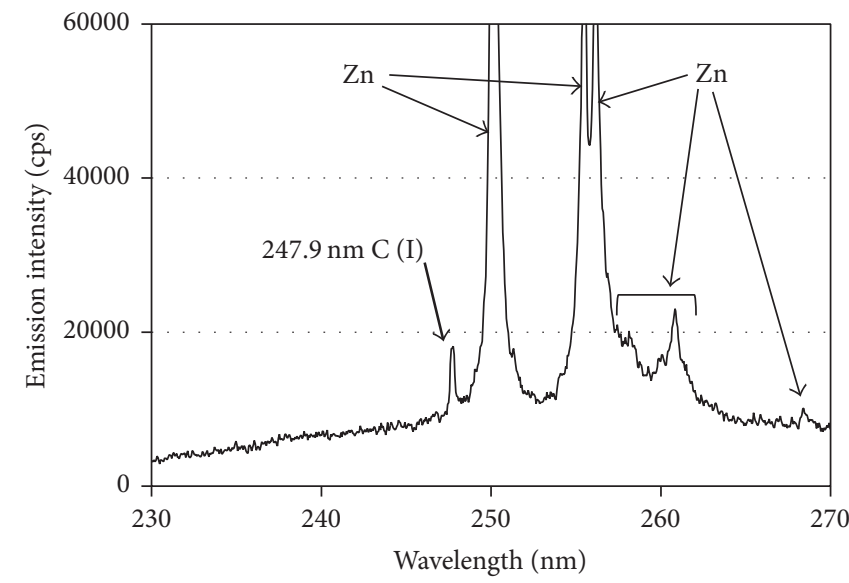

(a)

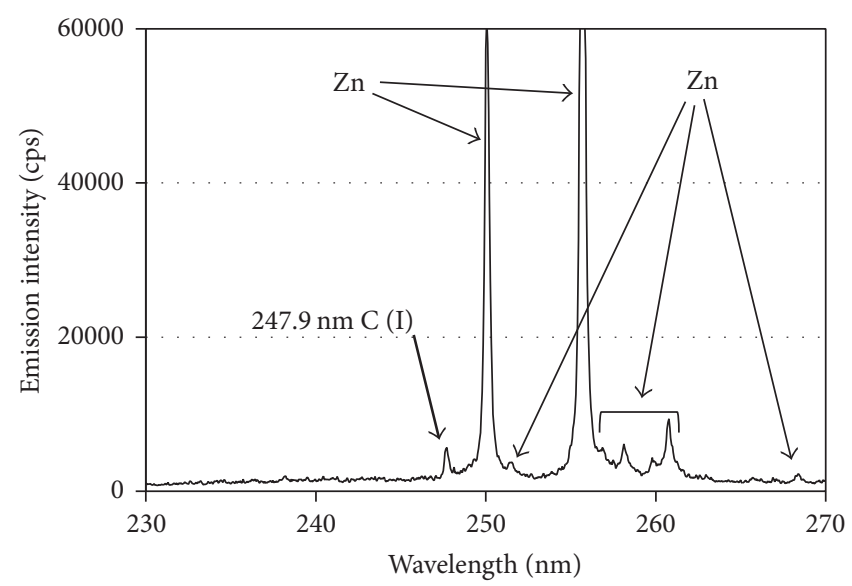

(b)

FIGURE 2: LIBS spectra observed for Zn under (a) Ar and (b) He chamber gas conditions.

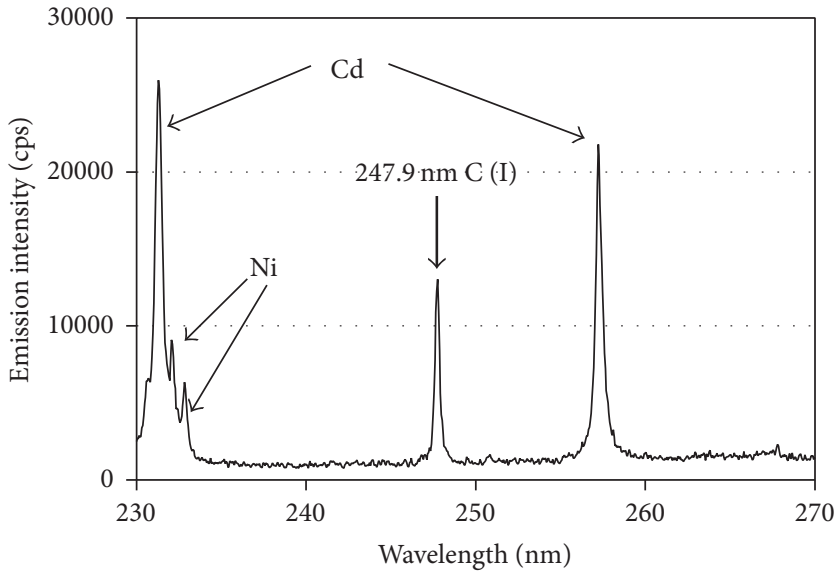

(a)

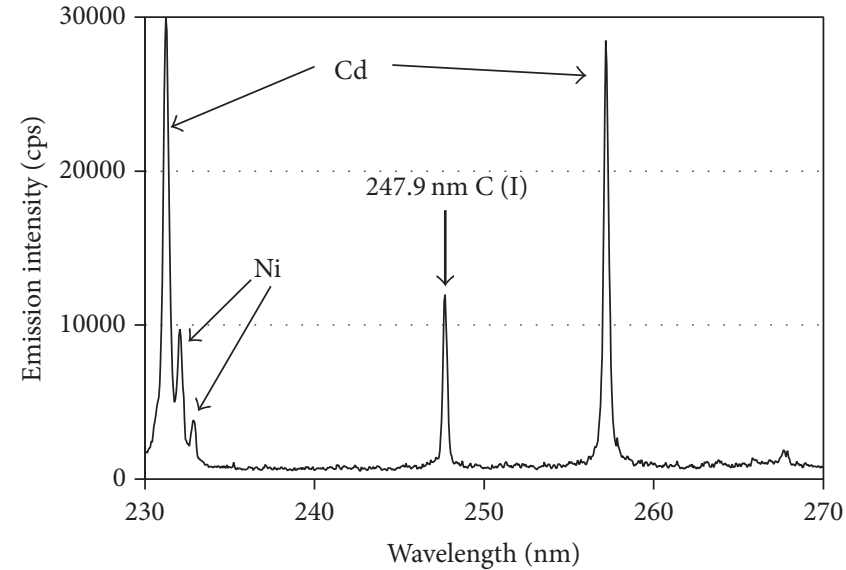

(b)

FIgURE 3: LIBS spectra observed for Cd under (a) Ar and (b) He chamber gas conditions.

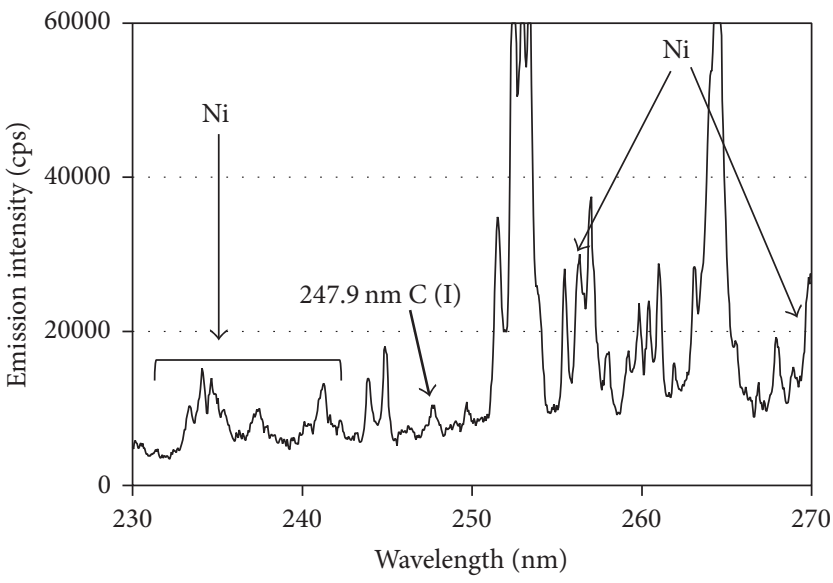

(a)

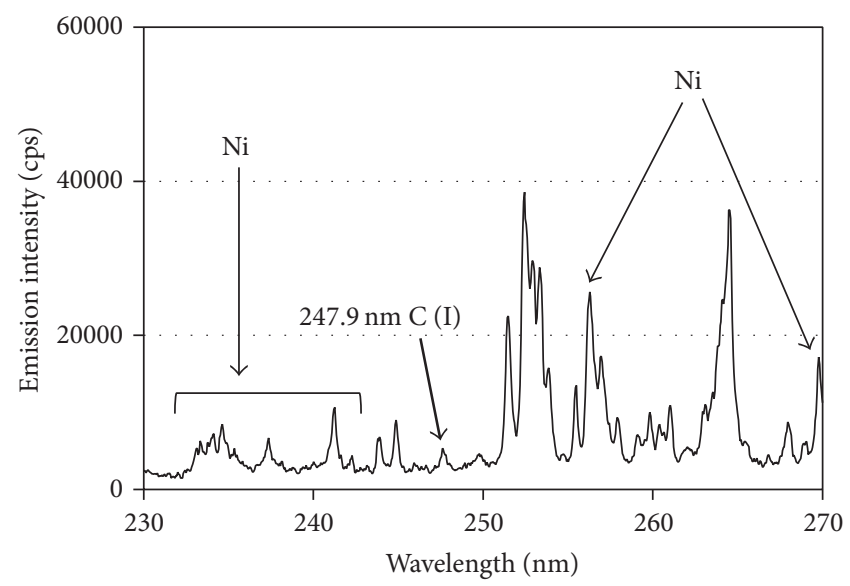

(b)

FIGURE 4: LIBS spectra observed for Ti under (a) Ar and (b) He chamber gas conditions. The emission spectra without indication of element were originated from $\mathrm{Ti}$. 


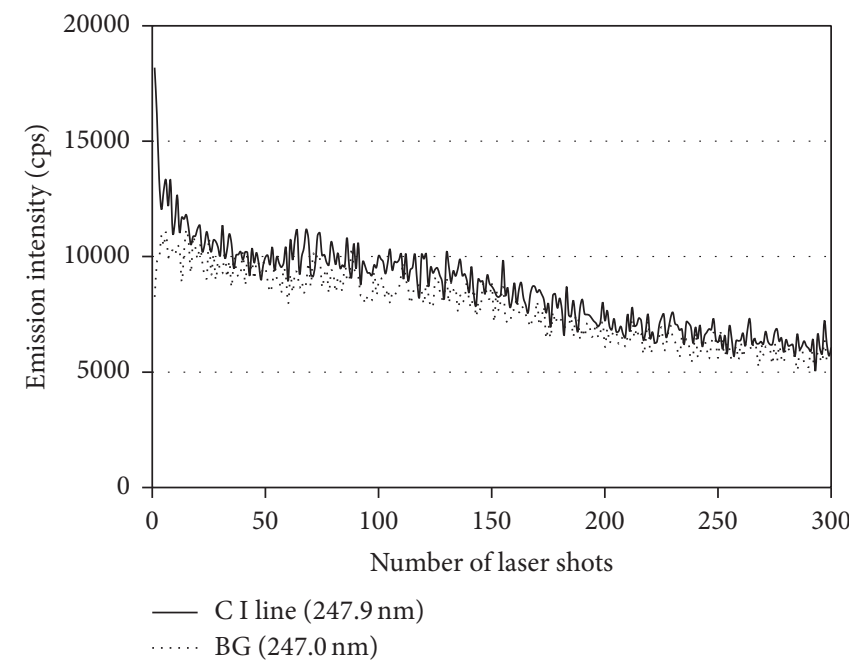

(a)

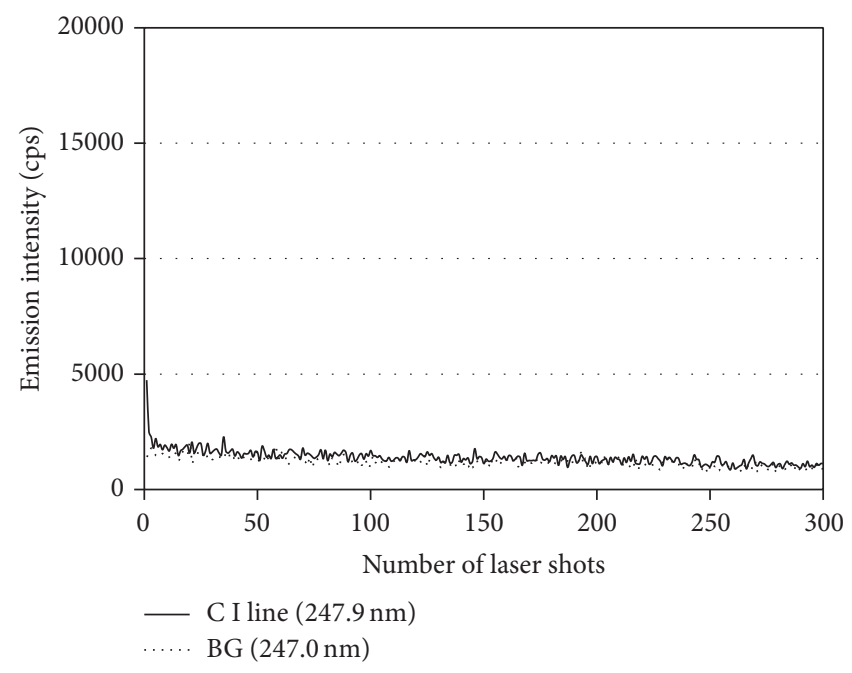

(b)

Figure 5: Emission signals from both C (247.9 nm) and background (247.0 nm) observed for Zn under (a) Ar and (b) He chamber gas conditions as a function of laser shots.

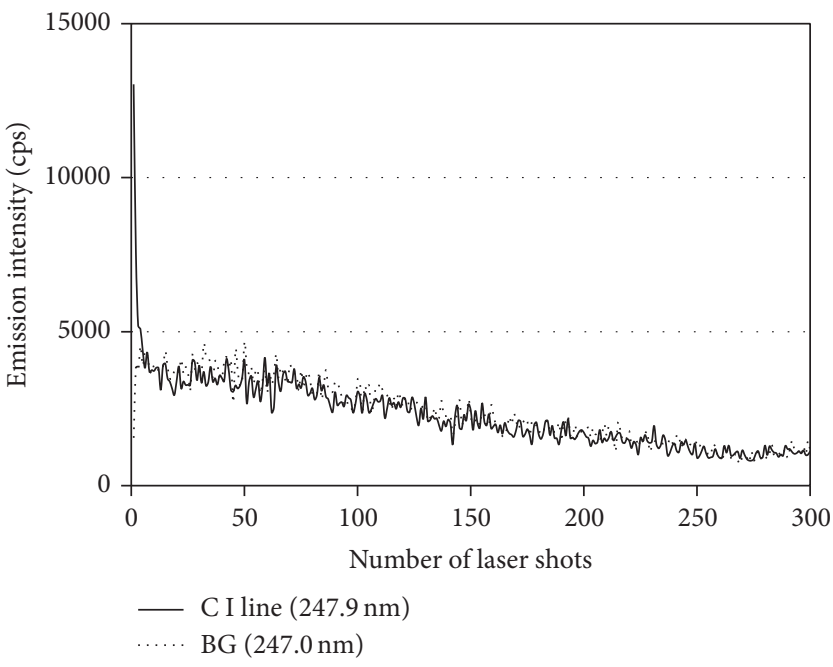

(a)

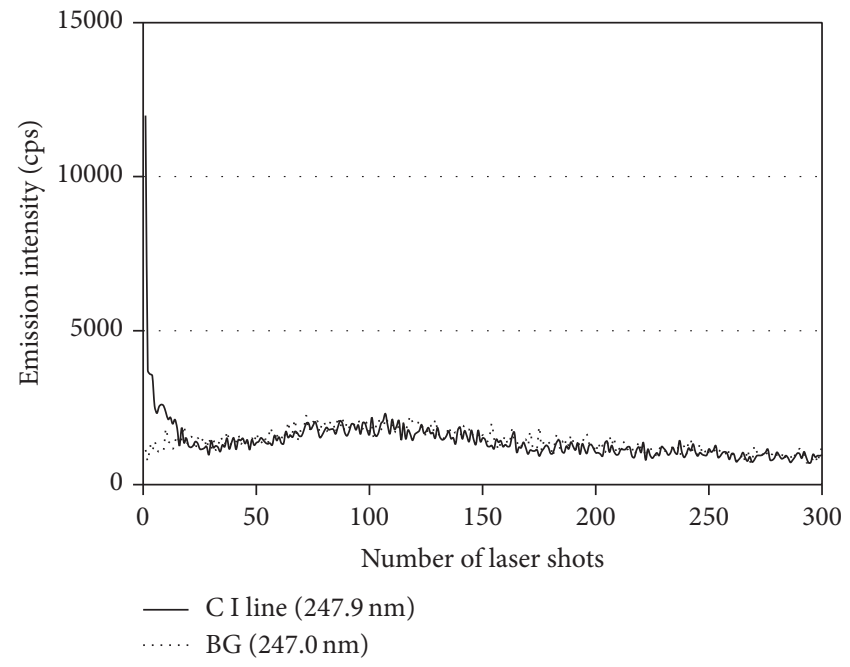

(b)

FIGURE 6: Emission signals from both C (247.9 nm) and background (247.0 nm) observed for Cd under (a) Ar and (b) He chamber gas conditions as a function of laser shots.

determined by oxygen combustion-infrared absorptiometry, the result was considered to be attributed to the $\mathrm{C}$ on metal surface. If the $\mathrm{C}$ atoms, which corresponded to the above concentrations of $\mathrm{C}$, were distributed homogeneously on the surface of the $2 \mathrm{~mm}$ cubic $\mathrm{Zn}$ metal, the $\mathrm{C}$ atom layers could be roughly estimated from 10 to 30 which corresponded to from 1.4 to $5.2 \mathrm{~nm}$ in depth. Since $c a .90 \mu \mathrm{m}$ in depth was obtained during 300 laser shots, estimated depth for each laser shot was $c a .300 \mathrm{~nm}$ which showed sufficiently deeper depth than the $\mathrm{C}$ layer. Therefore, strong $\mathrm{C}$ signal was only observed for the 1st laser shot as shown in Figures 5 and 6. On the other hand, as can be seen in Figure 7, C in Ti seemed to be distributed in bulk because the differences between $\mathrm{C}$ and background signals could be observed during 300 laser shots, even though the differences decreased with increasing laser shots which could be due to the laser beam defocusing. The detection limits of $\mathrm{C}$ in Ti were estimated and the values of $30-50 \mathrm{mg} \mathrm{kg}^{-1}$ could be obtained during the number of laser shots from 1st to 50th for both chamber gas conditions. From these results, the LIBS with a frequency quintupled $213 \mathrm{~nm}$ Nd:YAG laser was also expected to be useful for depth analysis of light elements as well as heavy elements as tandem LA/LIBS with ICPMS.

\section{Conclusion}

The LIBS with a frequency quintupled $213 \mathrm{~nm}$ Nd:YAG laser was examined for trace level of $\mathrm{C}$ analysis in high-purity 


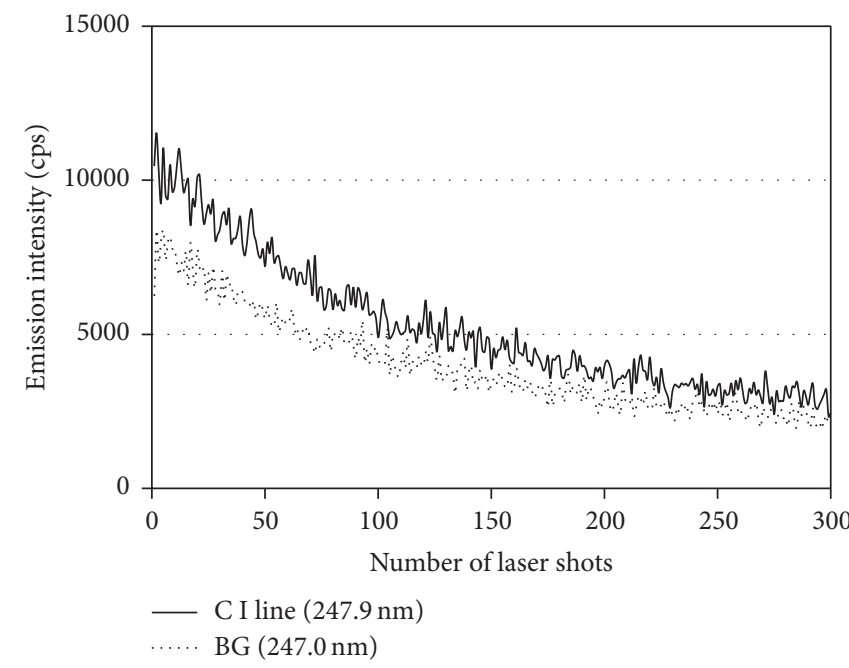

(a)

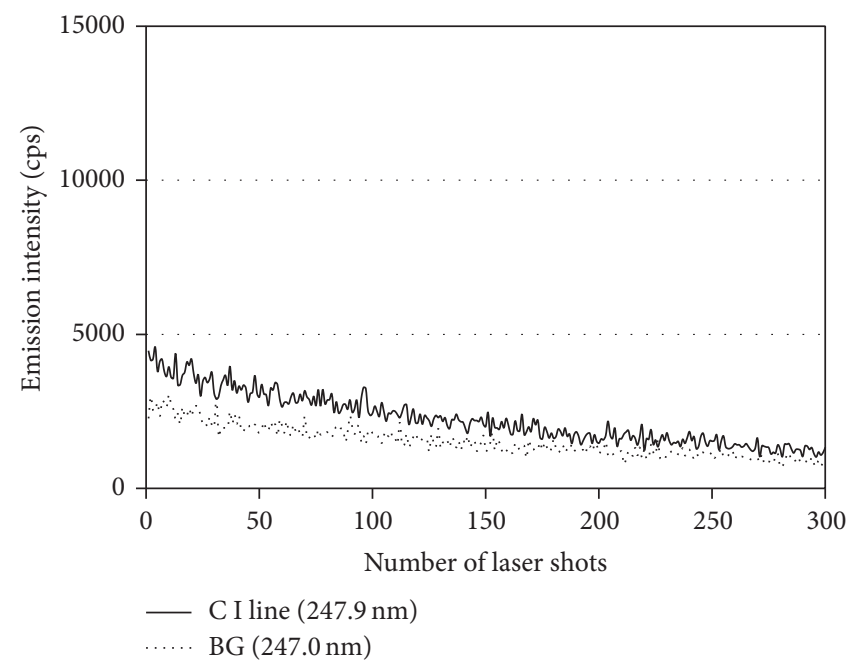

(b)

Figure 7: Emission signals from both C $(247.9 \mathrm{~nm})$ and background $(247.0 \mathrm{~nm})$ observed for Ti under (a) Ar and (b) He chamber gas conditions as a function of laser shots.

metals such as $\mathrm{Zn}, \mathrm{Cd}$, $\mathrm{Ti}$, and $\mathrm{Fe}$. The operating conditions including chamber gases such as $\mathrm{Ar}$ and He were examined. Though C emission signals in a wavelength of $247.9 \mathrm{~nm}$, which showed the highest sensitivity of $\mathrm{C}$, could be obtained from $\mathrm{Cd}$, Ti, and $\mathrm{Zn}, c a$. $7000 \mathrm{mg} \mathrm{kg}^{-1} \mathrm{C}$ in Fe could not be detected due to the interferences from a lot of $\mathrm{Fe}$ spectra. Alternative C signal in a wavelength of $193.1 \mathrm{~nm}$ could not be also detected from $\mathrm{Fe}$ due to the insufficient laser output energy of the frequency quintupled $213 \mathrm{~nm}$ Nd:YAG laser. In case of the depth analysis, the $\mathrm{C}$ in both $\mathrm{Cd}$ and $\mathrm{Zn}$ was found to be contaminated in only surface area, whereas the $\mathrm{C}$ in Ti was distributed in bulk. From these results, though the laser output energy was insufficient for $\mathrm{C}$ analysis in $\mathrm{Fe}$, the frequency quintupled $213 \mathrm{~nm} \mathrm{Nd:YAG} \mathrm{laser,} \mathrm{which} \mathrm{was}$ adopted widely for commercial LA system for trace element analysis in solid materials coupled with ICPMS, could be useful for $\mathrm{C}$ analysis to achieve simultaneous measurements for both $\mathrm{C}$ and trace elements in some metals by LIBS and LA-ICPMS, respectively.

\section{Competing Interests}

The authors declare that there is no conflict of interests regarding the publication of this paper.

\section{References}

[1] P. Harvey, Ed., Engineering Properties of Steel, American Society for Metals, Cleveland, Ohio, USA, 1982.

[2] V. B. E. Thomsen, Mpdern Spectrochemical Analysis of Metals, ASM International, 1996.

[3] R. Noll, Laser-Induced Breakdown Spectroscopy: Fundamentals and Applications, Springer, 2012.

[4] J. A. C. Broekaet, Analytical Atomic Spectrometry with Flames and Plasmas, Wiley-VCH, 2005.
[5] J. Plsonero and D. Günther, "Femtosecond laser ablation inductively coupled plasma mass spectrometry: fundamentals and capabilities for depth profiling analysis," Mass Spectrometry Reviews, vol. 27, no. 6, pp. 609-623, 2008.

[6] N. H. Bings, A. Bogaerts, and J. A. C. Broekaert, "Atomic spectroscopy," Analytical Chemistry, vol. 80, no. 12, pp. 43174347, 2008

[7] J. Pisonero, B. Fernández, and D. Günther, "Critical revision of GD-MS, LA-ICP-MS and SIMS as inorganic mass spectrometric techniques for direct solid analysis," Journal of Analytical Atomic Spectrometry, vol. 24, no. 9, pp. 1145-1160, 2009.

[8] M. Resano, E. García-Ruiz, and F. Vanhaecke, "Laser ablationinductively coupled plasma mass spectrometry in archaeometric research," Mass Spectrometry Reviews, vol. 29, no. 1, pp. 55$78,2010$.

[9] Z. Y. Qin, J. A. Caruso, B. Lai, A. Matusch, and J. S. Becker, "Trace metal imaging with high spatial resolution: applications in biomedicine," Metallomics, vol. 3, no. 1, pp. 28-37, 2011.

[10] A. Sussulini and J. S. Becker, "Combination of PAGE and LAICP-MS as an analytical workflow in metallomics: state of the art, new quantification strategies, advantages and limitations," Metallomics, vol. 3, no. 12, pp. 1271-1279, 2011.

[11] J. Koch and D. Günther, "Review of the state-of-the-art of laser ablation inductively coupled plasma mass spectrometry," Applied Spectroscopy, vol. 65, no. 5, 2011.

[12] M. Ohata, D. Tabersky, R. Glaus, J. Koch, B. Hattendorf, and D. Günther, "Comparison of $795 \mathrm{~nm}$ and $265 \mathrm{~nm}$ femtosecond and $193 \mathrm{~nm}$ nanosecond laser ablation inductively coupled plasma mass spectrometry for the quantitative multi-element analysis of glass materials," Journal of Analytical Atomic Spectrometry, vol. 29, no. 8, pp. 1345-1353, 2014.

[13] M. Ohata, N. Nonose, L. Dorta, and D. Günther, "Comparison of $265 \mathrm{~nm}$ femtosecond and $213 \mathrm{~nm}$ nanosecond laser ablation inductively coupled plasma mass spectrometry for $\mathrm{Pb}$ isotope ratio measurements," Analytical Sciences, vol. 31, no. 12, pp. 1309-1315, 2015. 
[14] J. A. Aguilera, C. Aragón, and J. Campos, "Determination of carbon content in steel using laser-induced breakdown spectroscopy," Applied Spectroscopy, vol. 46, no. 9, pp. 1382-1387, 1992.

[15] C. Aragón, J. A. Aguilera, and J. Campos, "Determination of carbon content in molten steel using laser-induced breakdown spectroscopy," Applied Spectroscopy, vol. 47, no. 5, pp. 606-608, 1993.

[16] V. Sturm, L. Peter, and R. Noll, "Steel analysis with laser-induced breakdown spectrometry in the vacuum ultraviolet," Applied Spectroscopy, vol. 54, no. 9, pp. 1275-1278, 2000.

[17] M. A. Khater, J. T. Costello, and E. T. Kennedy, “Optimization of the emission characteristics of laser-produced steel plasmas in the vacuum ultraviolet: significant improvements in carbon detection limits," Applied Spectroscopy, vol. 56, no. 8, pp. 970983, 2002.

[18] L. Peter, V. Sturm, and R. Noll, "Liquid steel analysis with laserinduced breakdown spectrometry in the vacuum ultraviolet," Applied Optics, vol. 42, no. 30, pp. 6199-6204, 2003.

[19] J. Wormhoudt, F. J. Iannarilli Jr., S. Jones, K. D. Annen, and A. Freedman, "Determination of carbon in steel by laser-induced breakdown spectroscopy using a microchip laser and miniature spectrometer," Applied Spectroscopy, vol. 59, no. 9, pp. 1098-1102, 2005.

[20] Y. Usui, T. Ishida, and K. Fujimoto, "Application of the double pulse Nd:YAG laser induced breakdown spectroscopy to on-site analysis of carbon in steel," Tetsu-to-Hagane, vol. 97, no. 2, pp. 76-80, 2011.

[21] M. A. Khater, "Application of laser-ablated plasmas to compositional analysis of steel in the vacuum ultraviolet," Journal of the Korean Physical Society, vol. 58, no. 6, pp. 1581-1586, 2011.

[22] M. A. Khater, "Laser-induced breakdown spectroscopy for light elements detection in steel: state of the art," Spectrochimica Acta-Part B Atomic Spectroscopy, vol. 81, pp. 1-10, 2013.

[23] T. A. Labutin, S. M. Zaytsev, A. M. Popov, and N. B. Zorov, "Carbon determination in carbon-manganese steels under atmospheric conditions by laser-induced breakdown spectroscopy," Optics Express, vol. 22, no. 19, pp. 22382-22387, 2014.

[24] S. N. Abdulmadjid, N. Idris, M. Pardede et al., "Sensitive analysis of carbon, chromium and silicon in steel using picosecond laser induced low pressure helium plasma," Spectrochimica Acta B, vol. 114, pp. 1-6, 2015.

[25] C. Latkoczy and T. Ghislain, "Simultaneous LIBS and LA-ICPMS analysis of industrial samples," Journal of Analytical Atomic Spectrometry, vol. 21, no. 11, pp. 1152-1160, 2006.

[26] R. E. Russo, X. Mao, J. J. Gonzalez, V. Zorba, and J. Yoo, "Laser ablation in analytical chemistry," Analytical Chemistry, vol. 85, no. 13, pp. 6162-6177, 2013.

[27] M. Dong, D. Oropeza, J. Chirinos et al., "Elemental analysis of coal by tandem laser induced breakdown spectroscopy and laser ablation inductively coupled plasma time of flight mass spectrometry," Spectrochimica Acta-Part B Atomic Spectroscopy, vol. 109, pp. 44-50, 2015.

[28] K. Subedi, T. Trejos, and J. Almirall, "Forensic analysis of printing inks using tandem laser induced breakdown spectroscopy and laser ablation inductively coupled plasma mass spectrometry," Spectrochimica Acta-Part B Atomic Spectroscopy, vol. 103104, pp. 76-83, 2015.

[29] Y. Lee, S.-H. Nam, K.-S. Ham et al., "Multivariate classification of edible salts: simultaneous laser-induced breakdown spectroscopy and laser-ablation inductively coupled plasma mass spectrometry analysis," Spectrochimica Acta-Part B Atomic Spectroscopy, vol. 118, pp. 102-111, 2016.
[30] M. Bonta, J. J. Gonzalez, C. Derrick Quarles, R. E. Russo, B. Hegedus, and A. Limbeck, "Elemental mapping of biological samples by the combined use of LIBS and LA-ICP-MS," Journal of Analytical Atomic Spectrometry, vol. 31, no. 1, pp. 252-258, 2016.

[31] M. Dong, X. Mao, J. J. Gonzalez, J. Lu, and R. E. Russo, “Timeresolved LIBS of atomic and molecular carbon from coal in air, argon and helium," Journal of Analytical Atomic Spectrometry, vol. 27, no. 12, pp. 2066-2075, 2012.

[32] H. A. Ardakani and S. H. Tavassoli, "Depth profile analysis of nanometric layers by laser-induced breakdown spectroscopy," Journal of Applied Spectroscopy, vol. 80, no. 1, pp. 153-157, 2013.

[33] R. Glaus and D. W. Hahn, "Fiber-coupled laser-induced breakdown and Raman spectroscopy for flexible sample characterization with depth profiling capabilities," Spectrochimica Acta B, vol. 100, pp. 116-122, 2014.

[34] J. Agresti and S. Siano, "Depth-dependent calibration for quantitative elemental depth profiling of copper alloys using laserinduced plasma spectroscopy," Applied Physics A: Materials Science and Processing, vol. 117, no. 1, pp. 217-221, 2014.

[35] J.-H. In, C.-K. Kim, S.-H. Lee, J.-H. Choi, and S. Jeong, "Rapid quantitative analysis of elemental composition and depth profile of $\mathrm{Cu}(\mathrm{In}, \mathrm{Ga}) \mathrm{Se}_{2}$ thin solar cell film using laser-induced breakdown spectroscopy," Thin Solid Films, vol. 579, pp. 89-94, 2015. 

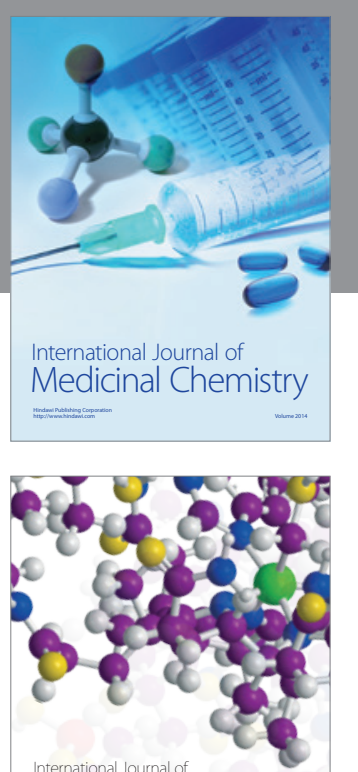

Carbohydrate Chemistry

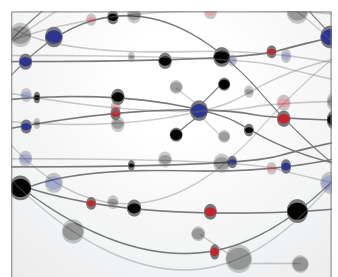

The Scientific World Journal
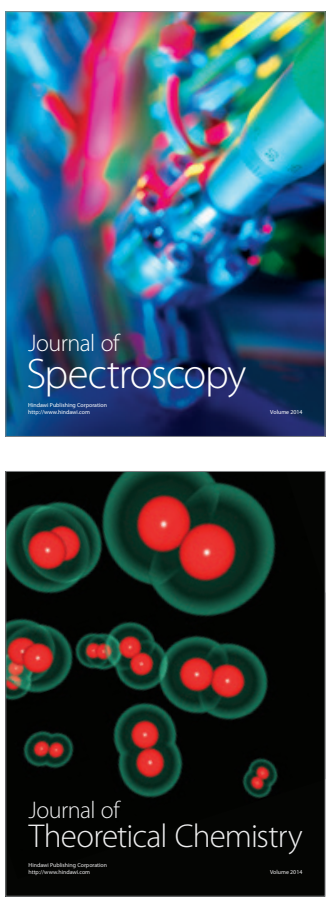
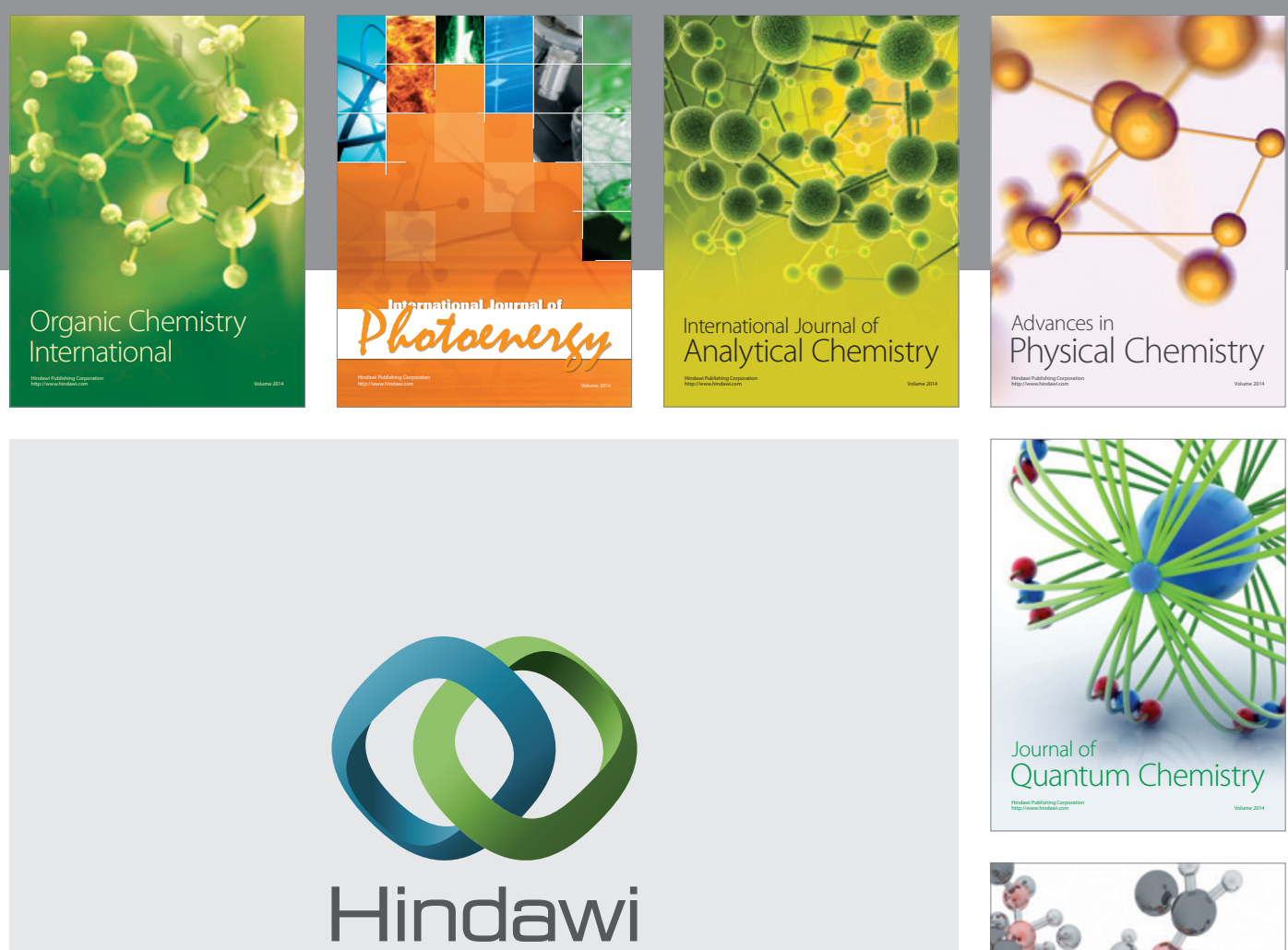

Submit your manuscripts at

https://www.hindawi.com

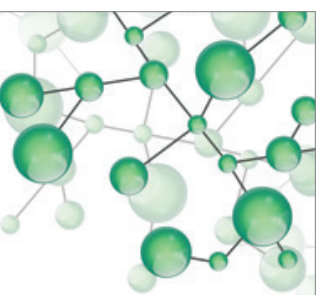

International Journal of

Inorganic Chemistry
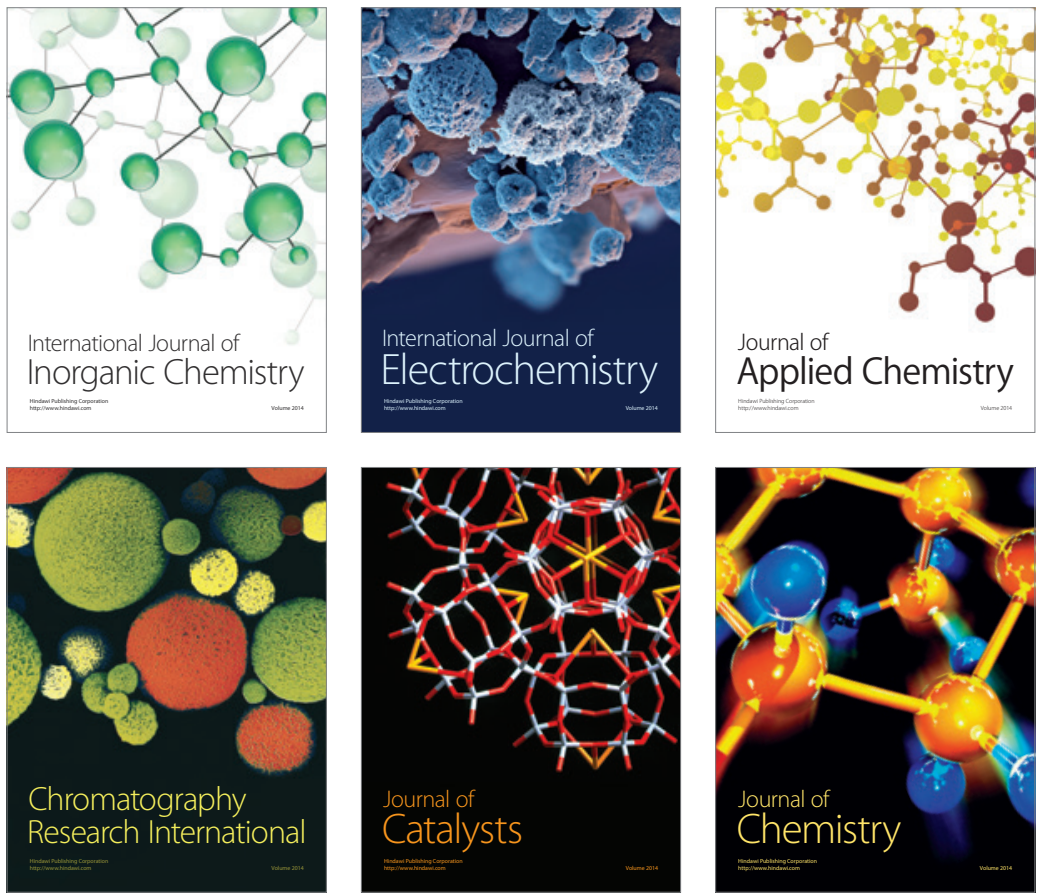

Journal of

Applied Chemistry
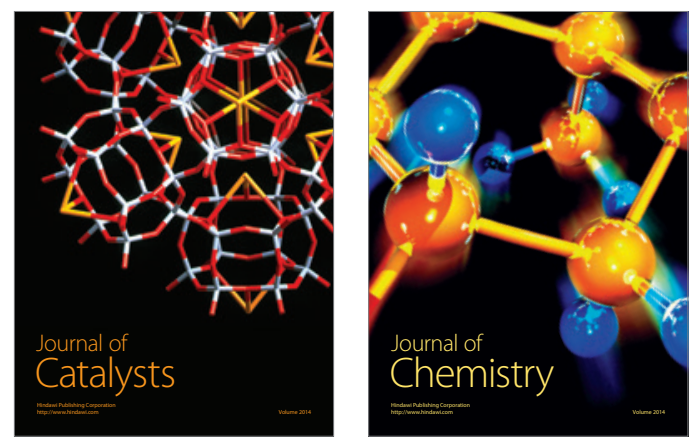
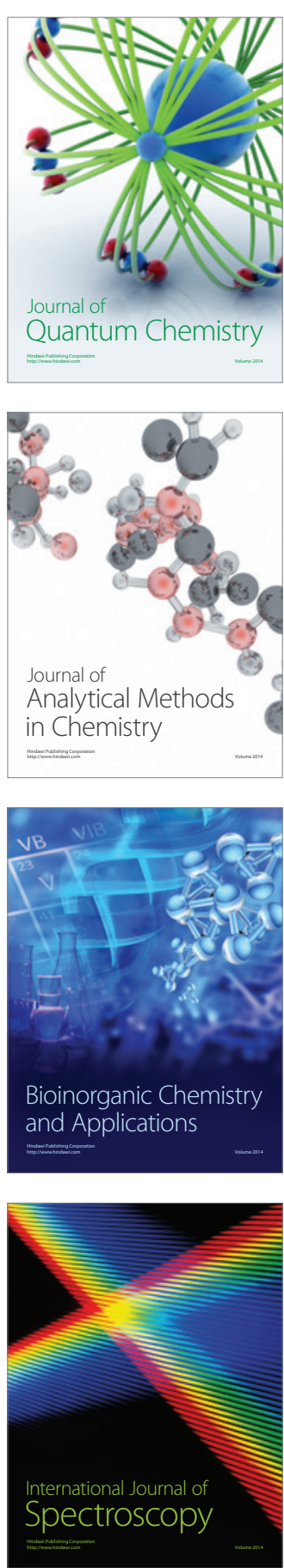